be a fraction of the asymptomatic vigabatrin-induced visual field defects that are unrecognized. At an international meeting in London, sponsored by Hoechst Marion Roussel, it was concluded that routine ophthalmological screening of all patients taking vigabatrin cannot be justified. Confrontational visual field examination is advised at baseline and follow-up of patients on vigabatrin, when practical. The risk:benefit ratio should be calculated for each individual, if visual field defects are uncovered. In infants receiving vigabatrin for the treatment of infantile spasms, the consensus argued that the benefits outweighed the risks. (Harding GFA. Benefit: risk ratio must be calculated for individual patients. BMI Jan 17, 1998;316:232-233).

\title{
NONCONVULSIVE SEIZURES AND BRAIN DAMAGE
}

Possible brain damage resulting from nonconvulsive seizures is debated "for" by Young GB and Jordan KG (Department of Clinical Neurological Sciences, 375 South St, London, Ontario, Canada N6A 4G5), and "against" by Aminoff MJ (Box 0114, Room M-794, Department of Neurology, School of Medicine, University of California, San Francisco, CA 94143). The brain damage school favors immediate and vigorous tratment of nonconvulsive status epilepticus (NCSE), whereas the non-damage group, while advocating treatment of NCSE, argues against potentially hazardous therapeutic extremes, such as general anesthesia. The section editor (Hachinski V) of these "Controversies in Neurology" concludes that both camps agree that brief absence seizures result in no detectable harm, though subtle cerebral changes may be difficult to detect. In balancing the potential harm of treatment compared with consequencies of nontreatment, antiepileptic side effects are usually transient, whereas sequelae of nontreatment may be cumulative and permanent. (Hachinski V. Nonconvulsive seizures and brain damage. Arch Neurol Jan 1998;55:120). (Respond: Vladimir Hachinski MD, Dept of Clinical Neurological Sciences, London Health Sciences Centre, 339 Windermere Rd, London, Ontario, Canada N6A 5A5).

COMMENT. In pediatric neurology, most practitioners have followed the occasional child with absence epilepsy whose seizures prove refractory to various mono- and polytherapies as well as the ketogenic diet. In some cases it is distressing to observe a gradual though inexorable cognitive impairment, rarely to the level of dementia. The cause of this regression may be unexplained, or linked to the nonconvulsive seizures or to the therapy or both. In some cases the drugs may be more injurious than the seizures, if sedative and cognitivedepressant doses are continued for long periods. In others, patients in unrecognized status absence epilepsy, a dramatic recovery of mental alertness may follow effective vigorous and acute, short-term therapy.

My colleague, Dr Cynthia Stack, Director of Neurophysiology and Electroencephalography at Children's Memorial Hospital, Chicago, was consulted. She is in favor of prompt and vigorous therapy of nonconvulsive status epilepticus in children. Dr Stack supports the theory that nonconvulsive status may signify a non-reactive and more severe state of brain damage than convulsive status epilepsy.

\section{POST-HEAD TRAUMA PROPHYLACTIC ANTICONVULSANTS}

The effectiveness and safety of antiepileptic agents in the treatment of acute traumatic head injury were determined at the Institute of Child Health, University College, London, UK, by review of 10 randomized controlled trials involving 2036 patients identified from various databases. The pooled relative risk (RR) for early seizure prevention (within the first week after injury) was $0.34 ; 10$ 